\title{
A Theory of Jurisdictional Assignments in Bureaucracies ${ }^{1}$
}

\author{
Michael M. Ting \\ Department of Political Science \\ University of North Carolina \\ Chapel Hill, NC 27599-3265 \\ Phone: (919) 962-0440 \\ Fax: (919) 962-0432 \\ mmting@unc.edu
}

February 8, 2002

\begin{abstract}
What determines the allocation of tasks among government agencies? This paper develops a formal model of task allocation that argues that jurisdictions are strategically designed to achieve legislative goals. In the model, agencies choose unobservable policies, and political outcomes are a noisy indicator of these choices. The legislature therefore faces a compliance issue when the agencies' policy preferences are different from its own. The legislature exerts control by defining agency jurisdictions, setting ex ante budgets and choosing ex post contractual inducements. The principal result is that tasks will be consolidated under a single roof when that agency prefers lower levels of policy than the legislature. In other cases, separating tasks prevents resources from being allocated in a manner undesirable for the legislature.
\end{abstract}

${ }^{1}$ The author wishes to thank David Baron and Jonathan Bendor for useful discussions. Justin Adams, Sean Gailmard, Tim McKeown, Ken Shotts, James Snyder, panel participants at the 1997 Midwest Political Science Association Meetings, and two anonymous referees also provided helpful comments. All mistakes are of course my own. 


\section{Introduction}

A fundamental issue in the design of bureaucratic systems is the assignment of tasks to agencies. Between 1924 and 1973, Congress established 246 agencies, many of which assumed responsibility for new tasks (Kaufman 1976). But during that period Congress also assigned countless new tasks to existing agencies, some of which were accepted happily while others generated resistance. What accounts for these variations? Federal and state agencies today collectively handle a multitude of tasks, but to a large degree the rationales for particular configurations of agency jurisdictions remain unclear.

Perhaps the most obvious explanation for how tasks are allocated is that they are arranged according to technical criteria. For any new task, an existing organization familiar with related tasks would seem likely to perform it most effectively. Thus, tasks involving naval warfare should be assigned to the Navy, tasks related to retirement insurance should be assigned to the Social Security Administration, and completely new and unrelated tasks should be assigned to new agencies. While the argument no doubt characterizes an important incentive for the designers of bureaucratic jurisdictions, it (perhaps surprisingly) fails to capture a great many interesting cases. Technical similarities are often difficult to discern ex ante. It was not obvious to policy-makers in the 1930s, for example, whether food and drug advertising should be regulated by the Food and Drug Administration or the Federal Trade Commission (Quirk 1980). Moreover, the argument seems hard-pressed to explain many cases of agency specialization ex post. Why, for instance, are alcohol, tobacco, and firearms enforcement separated from the Drug Enforcement Agency? Finally, even in some cases where the technical explanation works, more general conclusions about the extent to which technology matters remain elusive. As the Social Security Administration's ineffective assumption of the Disability Insurance program illustrates (Derthick 1990), it is often clear retrospectively that agencies have difficulties performing new and different tasks. Yet other agencies, like the Forestry Service, have historically performed seemingly vast portfolios of dissimilar tasks with great success (Kaufman 1960).

The prevalence of such technically counterintuitive task assignments naturally leads to a consideration of alternative rationales for task allocation. One important argument is that an optimal jurisdictional allocation might entail separating tasks which share technical similarities 
across agencies. By making bureaucratic systems redundant, political principals can insure themselves against random failures in individual agencies (Landau 1969). While this perspective does not embody a comprehensive theory of task allocation, its amenability to formalization has resulted in the valuable theoretical contribution of making explicit the incentives of political principals (Bendor 1985, Heimann 1993).

\section{The Strategic Allocation of Agency Tasks}

This paper adopts a third perspective, which differs from redundancy theory in two ways. First, instead of asking when a task is assigned to multiple agencies, it considers when an agency will be assigned multiple tasks. Second, it additionally considers the strategic incentives of agencies and other relevant interests in the political process.

These topics are explored to some degree by two prominent works. Moe (1989) argues that a task's bureaucratic home reflects the preferences of the interest groups and legislators concerned with its performance. For example, an enacting coalition might shield a task from future political attacks by placing it within a "friendly" department, or by assigning it to an independent commission. Wilson (1989) attempts to explain why even expansionist bureaus frequently shun new responsibilities. ${ }^{2}$ The Federal Bureau of Investigation, for instance, resisted participation in narcotics investigations, and the Navy and Air Force have historically neglected sealift and airlift, respectively. Far from being aberrations, these tasks have a clear technical relation with the activities of their host agencies, as well as an ability to inflate budgets. Nevertheless, such tasks were resisted because they might cause agencies to lose their "sense of mission," impose additional costs, and introduce additional opportunities for failure. ${ }^{3}$

These arguments are informal and leave some room for interpretation, but they establish that the placement of tasks is of critical importance to its supporters and opponents, as well as to the agencies themselves. Further, they suggest some of the central features of a theory of task allocation. Because task sets affect agencies' performance incentives, and designers anticipate these incentives, jurisdictional allocations are usefully analyzed as equilibrium phenomena. The

\footnotetext{
${ }^{2}$ Perhaps echoing some popular attitudes in America, a staple of economic analyses of bureaucratic politics is the assumption that agencies maximize budgets or size (Tullock 1965, Niskanen 1971). In fact, this assumption is often accepted as the cardinal distinction between bureaus and firms (see Miller and Moe 1983).

${ }^{3}$ In a somewhat different vein from the argument developed here, Wilson also argues that adding tasks can introduce competing agencies or additional principals (e.g., more Congressional oversight committees). The latter scenario is addressed to some degree by common agency models (e.g., Dixit 1995).
} 
game theoretic model developed here will therefore address a host of important but as yet unanswered questions. ${ }^{4}$ How exactly do multiple tasks affect the incentives of agencies? Is compliance better assured by handing a task to a new agency (or commission) or assigning it to a "friendly" agency? Would legislative principals attempt to induce better performance out of "unfriendly" agencies by merging them with "friendly" ones? By answering these questions, the model will also aid the construction of empirical tests.

\section{Explaining Task Allocations}

The model is centered around a hierarchical relationship between agencies and their most important principal, the legislature. ${ }^{5}$ As Wilson and Moe suggest, this environment is characterized by numerous tensions. The actors' policy preferences may diverge because legislatures do not fully control the appointment of bureau heads, or because of pressure from an assigned task's constituencies (e.g., Hammond 1979). Combined with imperfect monitoring, the bureaucratic allocation of resources can then pose serious compliance issues. ${ }^{6}$ A natural framework, then, for analyzing problems with this structure is the principal-agent contracting model (Dixit 1995, de Figueiredo 1998).

Unfortunately, this approach presents a major difficulty in the context of agency budgeting. A contractual payment does not constrain the ex ante feasibility of an agent's policy choices, but rather serves as ex post compensation. However, a crucial part of a legislature's "Power of the Purse" is the ability to use the budget not only to reward agencies but also to delimit their feasible actions ex ante.

\footnotetext{
${ }^{4}$ To see why formalization of these insights is necessary, consider Wilson's explanations for why agencies resist new tasks. First, the "sense of mission" argument is susceptible to the same criticisms as the assessment of technical similarities between tasks. Second, the cost argument cannot explain why a legislature would not fund additional tasks adequately. It is possible that budgeters operate under a fiscal illusion when facing multi-task agencies, perhaps in the form of a lag between the time at which additional costs are incurred and when a sufficient budget is provided. But if a legislature were well-apprised of policy costs, the real problem for the agency might well be a loss of "slack" rather than an increase in costs. Finally, policy failures are certainly bad for bureaus, but the argument lacks a discussion of the implications of failure. Without some notion of the punishment scheme that an agency faces, it is difficult to draw conclusions about whether it would resist an additional task.

${ }^{5}$ See Kaufman (1981). Legislatures are the most natural choice for agencies' political principals for this model, since they exert direct control over agencies' budgets and task sets. An interesting extension would be to explore the addition of other principals such as interest groups and the president.

${ }^{6}$ The model therefore does not feature incomplete information. However, it is worth considering the possibility that a consolidated agency would be better informed than the principal about the proper allocation of resources. Such a model might resemble models of delegation under incomplete information (e.g., Epstein and O’Halloran 1999).
} 
The game developed here is based on a contracting model, but it addresses this concern by considering both ex ante and ex post controls. It makes two assumptions about the policy technology available to agencies. First, budgets may be freely allocated across assigned jurisdictions or consumed as slack. This comports with the casual observation that agencies in practice frequently have considerable leeway in exercising policy priorities. ${ }^{7}$ Second, utility across tasks are additively separable. Thus, there are no exogenous efficiency gains from consolidating tasks. This assumption allows the strategic aspect of task allocation to be studied in isolation of technological factors.

In the game, the legislature first chooses whether to consolidate tasks under one agency, or separate them into a set of single-task agencies. It then sets a budget and a contract for each agency. The budget delimits ex ante an agency's feasible policy space, while the contract specifies the ex post payment to be delivered for each outcome in an agency's jurisdiction. Each agency then chooses a costly policy that is feasible under its assigned budget, unobserved by the legislature. ${ }^{8}$ Upon observing the outcomes of these policies (which are correlated with the policy choices), the legislature delivers the promised contractual payments. These payments may be construed in a number of ways, such as less stringent oversight, greater program autonomy, approval of friendly appointees, or favorable future budgetary treatment. ${ }^{9}$

Several non-obvious and testable predictions concerning the allocation of tasks result.

\footnotetext{
${ }^{7}$ While legislatures often specify how funds are distributed across tasks, agencies that undertake complex tasks have various methods of working around such requirements to satisfy urgent needs or pursue other policy goals. In the 1990s, for example, the California State Assembly and Senate attempted with limited success to impose a new accounting system on the Department of Transportation (Caltrans) to ensure that it complied with legislative spending wishes. A report produced by the consultancy SRI International (1996: 15) concluded that "Unfortunately, yet not unusually for government agencies, no consistent measure of output could be identified. Furthermore, Caltrans had no set of overall department measures that disaggregated into division, functional unit, project, and individual staff targets to be used as the basis for regularly tracking achieved performance versus target and for annual performance reviews."

${ }^{8}$ This scenario accords particularly well with Wilson's (1989) notion of craft agencies, or organizations whose activities are difficult to observe, such as the Army Corps of Engineers or Food and Drug Administration. Under these conditions, budgets assume a particularly important role because administrative rules (e.g., McCubbins, Noll, and Weingast 1987) are less likely to be effective.

${ }^{9}$ A further difficulty with contracting models is the assumption of commitment to the compensation (or punishment) schedule. This assumption is a non-trivial matter in political settings, where there are no courts to make promises of payment credible. Since agencies must request new budgets annually, it is sometimes justified as a convenient way to incorporate the effects of repeated play in a single-period game (e.g., Bendor, Taylor, and Van Gaalen 1987). Nevertheless, it is sometimes unclear whether the behavior predicted by such a single-period game is supportable in a non-cooperative context (see, e.g., Banks 1989). It is possible to show, however, that the equilibrium strategies of the game developed here are sustainable as the Nash equilibrium strategies of a repeated game (proof available upon request from author).
} 
The equilibrium allocation depends on the relative effectiveness of the ex ante and ex post controls, which in turn depend on the policy preferences of the players. Consolidation allows the principal to write a contract that disproportionately awards good performance on all tasks. This gives a multi-task agency a greater incentive to perform on all tasks than a contract that rewards each task independently. Thus if the legislature desires higher levels of output than the agency on all tasks, it may be in her best interest to consolidate tasks. Otherwise, if the legislature wants less effort on a task, consolidation may distort the allocation of effort toward the less desired task. In this case, separation ensures that the ex ante budgets are not mis-allocated, and the legislature can typically achieve her optimal policy on at least one task at minimum cost and with no contractual payment.

The model complements a variety of formal work on task and resource allocation in hierarchical relationships. Its "hidden action" setup distinguishes it from previous game theoretic models of agency budgeting, which assume informational asymmetries in a singleperiod setting (Banks 1989, Banks and Weingast 1992) or observable policies in a repeated setting (Silver 1996, Calvert, McCubbins, and Weingast 1989). The latter category of models appeal to Folk Theorems to derive their results, showing that many policies are supportable in equilibrium when actions are observable. By comparison, the equilibrium budgets and policies for each jurisdictional subgame in this model are unique. The model also contrasts usefully with contracting models. Perhaps the most relevant work in this area is Holmstrom and Milgrom's (1991) study of multi-task agents, which finds that a principal will want to ban tasks that agents value much more highly than the principal, since these tasks will divert the agents' efforts excessively. ${ }^{10}$ This result is similar in spirit to that of this paper, but the model developed here differs in two ways. First, all tasks are mandated by law, and so must be allocated to agents somehow. Second, the principal enjoys ex ante budget control, which powerfully affects her ability to obtain optimal outcomes under some conditions.

The remainder of the paper proceeds as follows. Section 2 introduces the model and characterizes the task allocation in the simple case where no ex post contracts are possible. The full game is examined in Section 3, which also establishes some simple requirements for

\footnotetext{
${ }^{10}$ The model also finds that the cost of providing optimal task incentives leads a principal to assign agents tasks that are similarly difficult to monitor.
} 
effective ex post contracts. In Section 4 I derive the main results, comparing the principal's anticipated payoff from consolidating policies to her payoff from assigning tasks to different agencies. Section 5 introduces a few empirical applications of the model's central findings, and Section 6 discusses the results and concludes.

\section{The Model}

\section{Environment and Sequence}

The model is single-period game of imperfect information. There are two tasks or policy dimensions, the outcomes of which are represented by the random vector $\mathbf{X}=\left(X_{1}, X_{2}\right)$. The outcome for task $i$ is either a success $\left(X_{i}=1\right)$ or failure $\left(X_{i}=0\right)$. Outcomes are the result of a two-element policy vector $\phi$ or $\phi^{C}$, depending on the allocation of tasks. It is assumed that $\phi_{i} \in$ $[0,1]$ and $\operatorname{Pr}\left\{X_{i}=1\right\}=\phi_{i}$. Policies are costly, as defined by the function $c(\phi)=\sum_{i} c_{i}\left(\phi_{i}\right)$, where $c_{i}\left(\phi_{i}\right)=m_{i} \phi_{i}^{2}$. The policy vector $\phi^{C}$ has identical properties.

There are two kinds of players; a political principal (P) and one or two agencies. Each player has linear preferences over policy outcomes and quasilinear utility over money. P receives one unit of utility for each success and zero otherwise. She chooses payment schemes for the agencies, but cannot directly affect outcomes. Each agency handles at least one task, though each task is handled by only one agency. The agency in charge of task $i$ receives $w_{i}$ for a success on that task and $z_{i}$ for a failure. ${ }^{11}$ This potential divergence in preferences conveniently incorporates the influence of external parties (most notably the executive branch) on agencies. As a result, an agency may exploit imperfect information to consume part of its budget as slack, or allocate resources away from one task and toward another. ${ }^{12}$

The game sequence, depicted in stylized form in Figure 1, clarifies the incentives of these players. Before the first period, $\mathrm{P}$ chooses an allocation of tasks across agencies. In particular, she may either consolidate tasks under an existing agency that already performs another task, or separate tasks by creating a new agency. In the former case, or the consolidation subgame, one

\footnotetext{
${ }^{11}$ Since $w_{i}$ and $z_{i}$ can be varied arbitrarily, normalizing P's outcome payoffs at one and zero does not sacrifice any generality. Further, P's strict preference for successes is innocuous, for if P's payoff from failure were greater than her payoff from success, then she need not deal with an agency to attain her most preferred outcome.

${ }^{12}$ While slack pervades organizations (Cyert and March 1963), the preference for slack also complements the policy preference assumption. A bureaucrat with an ideal policy would ideally wish to spend just enough to attain her most desired policy and keep the remainder as slack.
} 
agency (A) performs both tasks. In the latter case, or the separation subgame, each task is performed by separate agencies (A1, A2) who care only about their own budgets and policy domains, and cannot transfer utility amongst themselves. In this regime P effectively collects payoffs from two independent games.

Following the jurisdictional allocation is a single cycle of budgeting and policy-making. $\mathrm{P}$ chooses an ex ante budget $B^{C} \geq 0$ in the consolidation subgame or a budget vector $\mathbf{B}=\left(B_{1}, B_{2}\right)$ in the separation subgame, where $B_{i} \geq 0$ is the budget given to $\mathrm{A} i$. $\mathrm{P}$ also chooses an ex post compensation for each agency in the form of a contract, which links all possible observable outcomes for that agency with a payment vector. It is assumed that $\mathrm{P}$ can commit credibly to delivering its announced payments. For the consolidated agency, the contract vector is $\boldsymbol{\beta}^{\boldsymbol{C}} \geq \mathbf{0}$. It will be convenient to define the elements of $\boldsymbol{\beta}^{\boldsymbol{C}}$ as follows. Let $\beta^{00}$ represent the payment for failures on both tasks, $\beta^{10}$ the payment for success on task 1 only, $\beta^{01}$ the payment for success on task 2 only, and $\beta^{11}$ the payment for success on both tasks. In the separation subgame, $\mathrm{P}$ chooses a contract $\boldsymbol{\beta}_{i}=\left(\beta_{i}^{0}, \beta_{i}^{1}\right) \geq \mathbf{0}$ for each $\mathrm{A} i$, where $\beta_{i}^{0}$ and $\beta_{i}{ }^{1}$ represents the payment for failure and success, respectively. The requirement that contractual payments be non-negative captures two features of bureaucratic politics. First, agencies do not have any resources other than those given by their principals (this is in the spirit of the assumption of ex ante budgets), and so P's ability to extract payments out of the agency is highly constrained. Second, individual bureaucrats have reservation values for continuing their employment. ${ }^{13}$

The agencies observe the budget and contract choices and then adopt policies within their jurisdictions, unobserved by P. In the consolidation subgame, A chooses policy vector $\boldsymbol{\phi}^{C}=\left(\phi_{1}{ }^{C}\right.$, $\phi_{2}{ }^{C}$ ), while in the separation subgame each agency A $i$ chooses component $\phi_{i}$ of the policy vector $\phi$. Agencies are subject to the constraints of their particular budgets: $c\left(\phi^{C}\right) \leq B^{C}$ for $\mathrm{A}$, and $c_{i}\left(\phi_{i}\right)$ $\leq B_{i}$ for A $i$. Agencies must consume any unexpended funds as slack. Finally, Nature determines policy outcomes $\mathbf{X}$ based on the selected policies, and P delivers its stated contractual payments.

\footnotetext{
${ }^{13}$ The assumption also prevents a trivial solution to the game: without it, $\mathrm{P}$ could induce an agency to choose its ideal policy with an appropriately-chosen schedule of negative payments.
} 


\section{Figure 1: Game Sequence}

\section{Consolidation Subgame:}

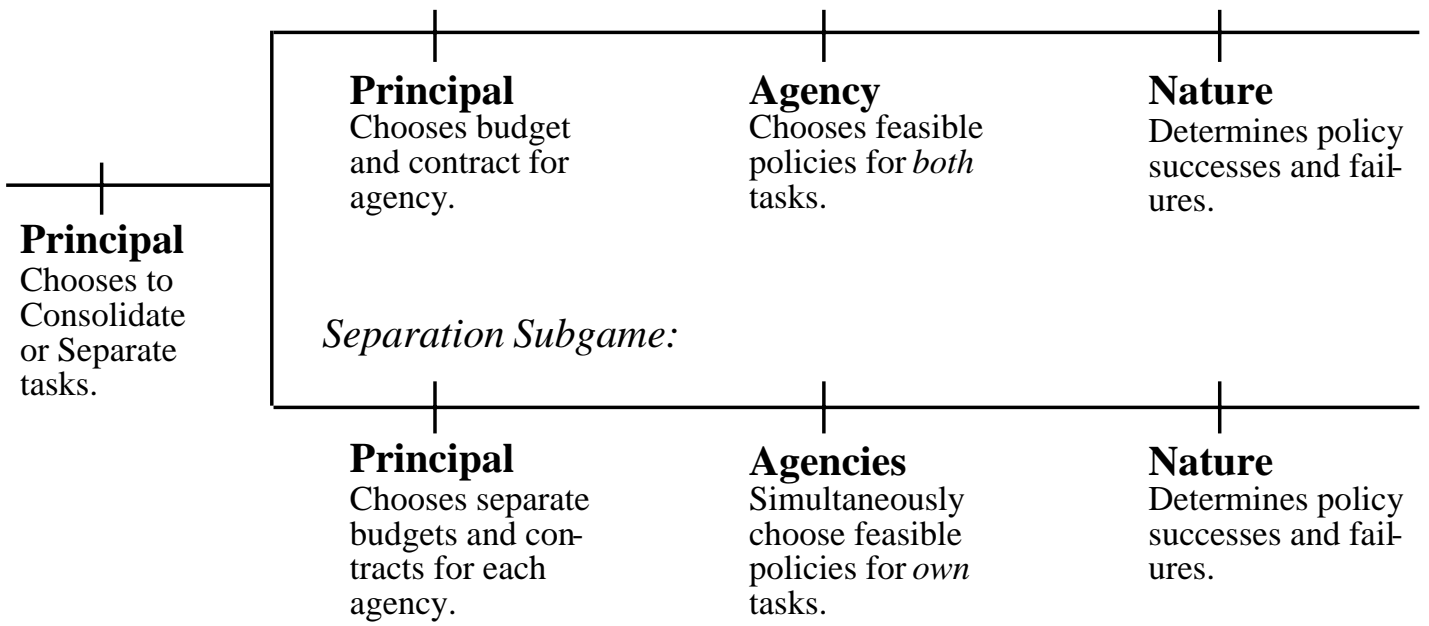

In the consolidation subgame, the expected utilities for $\mathrm{A}$ and $\mathrm{P}$ are therefore:

$$
\begin{aligned}
& u^{A}\left(\boldsymbol{\phi}^{C} ; B^{C}, \boldsymbol{\beta}^{C}\right)=\sum_{i}\left[w_{i} \phi_{i}^{C}+z_{i}\left(1-\phi_{i}^{C}\right)-c_{i}\left(\phi_{i}{ }^{C}\right)\right]+B^{C} \\
& \quad+\beta^{11} \phi_{1}{ }^{C} \phi_{2}{ }^{C}+\beta^{10} \phi_{1}{ }^{C}\left(1-\phi_{2}{ }^{C}\right)+\beta^{01}\left(1-\phi_{1}{ }^{C}\right) \phi_{2}^{C}+\beta^{00}\left(1-\phi_{1}{ }^{C}\right)\left(1-\phi_{2}{ }^{C}\right), \\
& u^{P}\left(B^{C}, \boldsymbol{\beta}^{C} ; \phi^{C}\right)=\sum_{i}\left[\phi_{i}^{C}\right]-B^{C} \\
& \quad-\beta^{11} \phi_{1}{ }^{C} \phi_{2}^{C}-\beta^{10} \phi_{1}^{C}\left(1-\phi_{2}{ }^{C}\right)-\beta^{01}\left(1-\phi_{1}{ }^{C}\right) \phi_{2}{ }^{C}-\beta^{00}\left(1-\phi_{1}{ }^{C}\right)\left(1-\phi_{2}^{C}\right) .
\end{aligned}
$$

Similarly, the expected utilities for $\mathrm{A} i$ and $\mathrm{P}$ in the separation subgame are:

$$
\begin{gathered}
u^{A i}\left(\phi_{i} ; B_{i}, \boldsymbol{\beta}_{i}\right)=w_{i} \phi_{i}+z_{i}\left(1-\phi_{i}\right)-c_{i}\left(\phi_{i}\right)+B_{i}+\beta_{i}^{1} \phi_{i}+\beta_{i}^{0}\left(1-\phi_{i}\right) \text { for each } \mathrm{A} i \\
u^{P}\left(\mathbf{B}, \boldsymbol{\beta}_{1}, \boldsymbol{\beta}_{2} ; \boldsymbol{\phi}\right)=\boldsymbol{\Sigma}_{i}\left[\phi_{i}-B_{i}-\beta_{i}{ }^{1} \phi_{i}-\beta_{i}^{0}\left(1-\phi_{i}\right)\right] .
\end{gathered}
$$

Note that there are no income effects, so budgets affect policy choices only if they constrain feasibility.

Subgame perfect Nash equilibria for this game are therefore characterized by an optimal jurisdictional choice by $\mathrm{P}$, along with budgets and contracts that maximize $u^{P}\left(B^{C}, \boldsymbol{\beta}^{C} ; \boldsymbol{\phi}^{C}\right)$ and $u^{P}\left(\mathbf{B}, \boldsymbol{\beta}_{1}, \boldsymbol{\beta}_{2} ; \boldsymbol{\phi}\right)$. Agency policy responses must maximize $u^{A}\left(\boldsymbol{\phi}^{C} ; B^{C}, \boldsymbol{\beta}^{C}\right)$ and $u^{A i}\left(\phi_{i} ; B_{i}, \boldsymbol{\beta}_{i}\right)$, subject to feasibility constraints.

For the subsequent analysis, it will be useful to define "unconstrained" ideal policies for each player. Let $\phi^{P}=\arg \max \sum_{i} \phi_{i}-c_{i}\left(\phi_{i}\right)$ be the policy $\mathrm{P}$ would choose if she paid for the policy herself. By the concavity of P's objective, $\phi^{P}$ is characterized by $\partial c_{i} / \partial \phi_{i}=1$ for each $i$ at 
an interior solution, and $\phi_{i}^{P}=1$ otherwise. Likewise, let $\phi^{4}=\arg \max \sum_{i}\left[\phi_{i} w_{i}+\left(1-\phi_{i}\right) z_{i}-c_{i}\left(\phi_{i}\right)\right]$ be the optimal policy vector for A if the budget constraint is slack. Since A's objective is concave, $\phi^{4}$ is characterized by the first-order condition $d c_{i} / d \phi_{i}=w_{i}-z_{i}$ for each $i$ at an interior solution, so that marginal policy utility equals marginal policy cost in every dimension. At a corner solution, $\phi_{i}^{A}=0$ if $w_{i} \leq z_{i}$ and $\phi_{i}^{A}=1$ if $d c_{i}(1) / d \phi_{i} \leq w_{i}-z_{i}$. Because A's utility is separable across dimensions, agency A $i$ 's ideal policy is identical to A's ideal in dimension $i$. Agency policy preferences therefore do not depend on the jurisdictional allocation. This effectively assumes that the same forces generate agency preferences (e.g., interest group pressure) regardless of whether tasks are consolidated. It also implies that there are no economies of scope to consolidation. As a result, the motives for particular jurisdictional allocations in the model are strategic, rather than economic.

\section{The No-Contracting Case}

As a baseline case, it will be helpful to derive jurisdictional assignments in the reduced game in which $\mathrm{P}$ cannot write contracts. In other words, suppose that contractual payments are constrained to $\boldsymbol{\beta}_{i}=\mathbf{0}$ and $\boldsymbol{\beta}^{C}=\mathbf{0}$ in their respective subgames. For generality, I consider an environment with $n \geq 1$ tasks.

This game has a unique subgame perfect equilibrium. Consider first the consolidation subgame, where A chooses a policy $\phi^{C}=\left(\phi_{1}{ }^{C}, \ldots, \phi_{n}{ }^{C}\right)$. Using backwards induction, A chooses the following policy vector for any budget $B^{C}$ :

$$
\begin{gathered}
\boldsymbol{\phi}^{C^{*}}\left(B^{C}\right) \in \arg \max \sum_{i}\left[\phi_{i}^{C} w_{i}+\left(1-\phi_{i}^{C}\right) z_{i}-c_{i}\left(\phi_{i}^{C}\right)\right]+B^{C}, \\
\text { subject to: } c\left(\boldsymbol{\phi}^{C}\right) \leq B^{C}, \boldsymbol{\phi}^{C} \geq \mathbf{0}, \boldsymbol{\phi}^{C} \leq \mathbf{1} .
\end{gathered}
$$

Call $\phi^{C^{*}}\left(B^{C}\right)$ the policy curve. This curve defines the set of policies such that, for any two tasks, the ratios of marginal utility and marginal cost are equal. ${ }^{14}$ Thus, policy vectors along it maximize A's return to effort. As Figure 2 illustrates for the two-task case, this curve consists of the tangent points between A's policy indifference curves and the budget constraint when $B^{C} \leq$ $c\left(\phi^{A}\right)$. Since A's objective function is quasilinear and strictly concave, $\phi^{C *}\left(B^{C}\right)$ is single-valued,

\footnotetext{
${ }^{14}$ This is subject to the policies being "interior," i.e., for $i \neq j, \phi_{i}^{C^{*}} \in(0,1)$ and $\phi_{j}^{C^{*}} \in(0,1)$, which is assured if $\phi^{A}<1$. Then solving the constrained maximization, it is easily shown that along the policy curve, $\phi_{i}^{C^{*}} / \phi_{j}^{C^{*}}$ $=m_{i}\left(w_{i}-z_{i}\right) / m_{i}\left(w_{i}-z_{i}\right)$. As a result, the policy curve in the no-contracting case is linear if $\boldsymbol{\phi}^{4}<\mathbf{1}$.
} 
continuous and weakly increasing in $B^{C}$.

Anticipating the policy response, the optimal budget $B^{C^{*}}$ satisfies:

$$
B^{C^{*}} \in \arg \max \sum_{i} \phi_{i}^{C^{*}}\left(B^{C}\right)-B^{C}, \text { subject to: } B^{C} \geq 0 \text {. }
$$

Thus, $\mathrm{P}$ chooses a budget that induces the policy on the policy curve that is "closest" to her ideal, $\phi^{P}$. In general, this budget equates P's marginal benefit from increasing the budget (possibly resulting in higher policies) with her marginal cost. It is easily shown that $B^{C^{*}}$ is unique. The equilibrium of the consolidation subgame is thus characterized by the pair $\left\{B^{C^{*}}, \phi^{C^{*}}\left(B^{C^{*}}\right)\right\}$.

\section{Figure 2: Two-Task Equilibrium of the No-Contracting Case}

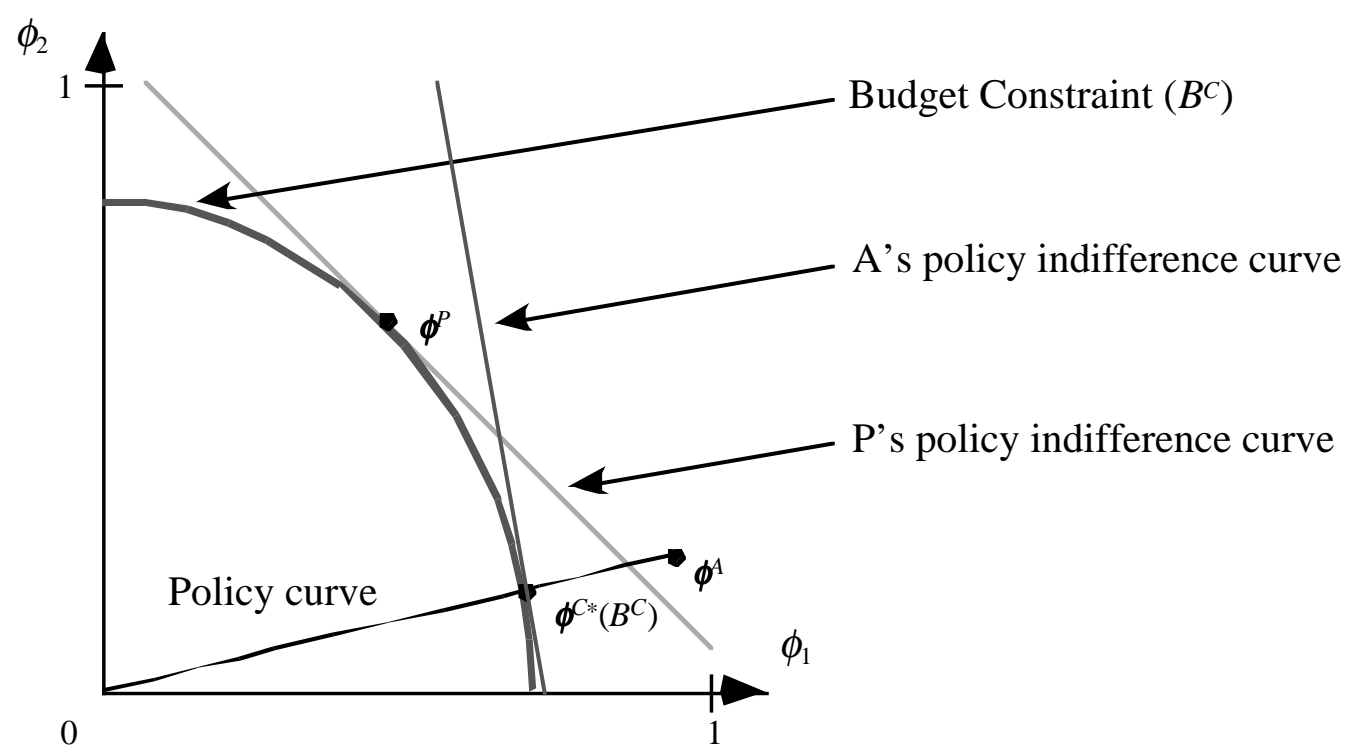

Because of the simplicity of the functional forms, it is straightforward to derive closed forms for equilibrium strategies. However, this is not essential for the task allocation decision. What matter are the boundaries of the policy curve and its implications for $\phi^{C^{*}}\left(B^{C}\right)$. At one extreme, it is clear that $\phi^{C *}(0)=\mathbf{0}$. At the other extreme, $\phi^{C^{*}}\left(B^{C}\right)=\boldsymbol{\phi}^{A}$ for $B^{C} \geq c\left(\phi^{4}\right)$, by the quasilinearity of A's preferences. In general, $\phi_{i}^{C^{*}}\left(B^{C}\right) \in\left[0, \phi_{i}^{A}\right]$ for all $B^{C}$, since A's utility is additively separable and $\phi_{i}^{A}$ is his ideal choice (if feasible) for task $i$. Thus, the equilibrium budget satisfies $B^{C^{*}} \leq c\left(\boldsymbol{\phi}^{4}\right)$, and there is no slack in equilibrium (i.e., $B^{C^{*}}=c\left(\boldsymbol{\phi}^{C^{*}}\left(B^{C^{*}}\right)\right)$ ) because A is either budget-constrained or not given any funds above $c\left(\phi^{A}\right)$. The absence of slack implies that $\mathrm{P}$ strictly prefers higher policies along the policy curve as long as $\boldsymbol{\phi}^{C^{*}}\left(B^{C}\right) \leq \boldsymbol{\phi}^{P}$. If $\boldsymbol{\phi}^{P} \geq \boldsymbol{\phi}^{4}$, 
then the closest point to $\boldsymbol{\phi}^{P}$ on the policy curve is $\boldsymbol{\phi}^{A}: B^{C^{*}}=c\left(\boldsymbol{\phi}^{A}\right)$ and $\boldsymbol{\phi}^{C *}\left(c\left(\boldsymbol{\phi}^{A}\right)\right)=\boldsymbol{\phi}^{A}$. For other values of $\phi^{P}$, P may choose an "interior" point on the policy curve (as in Figure 2). Note that $\boldsymbol{\phi}^{P}$ cannot be the equilibrium policy unless it lies along the policy curve.

In the separation subgame, equilibrium budgets and policies are easier to characterize because each A $i$ maximizes over one dimension and P's payoffs are additively separable. Thus, each task may be addressed separately. If $\phi_{i}^{A} \geq \phi_{i}^{P}$ (i.e., $\left.w_{i}-z_{i} \geq 1\right)$, then $\phi_{i}^{P}$ lies along the policy curve. $\mathrm{P}$ can get exactly her ideal policy by setting a budget $B_{i}^{*}=c_{i}\left(\phi_{i}^{P}\right)$, as $\phi_{i}^{*}\left(c_{i}\left(\phi_{i}^{P}\right)\right)=\phi_{i}^{P}$. If $\phi_{i}^{A}<\phi_{i}^{P}$, the result is similar to the special case above of a principal that is more ambitious than a consolidated agency: $B_{i}{ }^{*}=c_{i}\left(\phi_{i}^{A}\right)$ and $\phi_{i}{ }^{*}\left(c_{i}\left(\phi_{i}^{A}\right)\right)=\phi_{i}^{A}$. Thus for each task $i, \phi_{i}{ }^{*}=\min \left\{\phi_{i}^{A}, \phi_{i}^{P}\right\}$. Aggregating across tasks, the equilibrium policy vector satisfies $\boldsymbol{\phi}^{*} \leq \boldsymbol{\phi}^{P} .^{15}$

Now consider P's jurisdiction allocation problem. From the above derivation, it is clear that if $\boldsymbol{\phi}^{4} \leq \boldsymbol{\phi}^{P}$, then $\boldsymbol{\phi}^{C^{*}}=\boldsymbol{\phi}^{*}=\boldsymbol{\phi}^{4}$ and the jurisdictional allocation is inconsequential. The following result uses the above-mentioned properties of both subgames to show that in other cases, $\mathrm{P}$ would prefer to separate tasks.

Proposition 1. In the subgame perfect equilibrium of the n-task, no-contracting jurisdictional allocation game, $P$ separates tasks.

Proof. Proofs of all Propositions and Comments may be found in the Appendix.

Thus without contracts, and without assuming increasing returns to scope from policy production or other cost benefits, $\mathrm{P}$ cannot gain from consolidating any number of tasks. Unless P's policy goals are all more ambitious than the agencies', consolidation reduces her control of budgetary resources across policies. Consolidation restricts $\mathrm{P}$ to maximize over only one budget, and hence over only the set of points along the policy curve. This restriction passes much of the surplus of the interaction to A. By contrast, separating the tasks allows $\mathrm{P}$ to fine-tune budgets, thereby protecting her from over-ambitious agencies. The result perhaps accords with the casual view that legislative principals have little leverage over multi-task agencies, but the subsequent section shows how ex post inducements can alter this conclusion.

\footnotetext{
${ }^{15}$ This intuition is quite robust across models that consider ex ante budget controls and agency policy preferences. Silver (1996) examines a continuous, unidimensional outcome space. Bendor and Moe (1985) study a simulation model with boundedly rational agencies.
} 


\section{The Separation and Consolidation Subgames}

Inow develop some preliminary results for each subgame that will both establish some intuition and serve as the basis for P's optimal jurisdictional allocation.

\section{The Separation Subgame}

Because P's payoffs are additively separable across agencies and agencies cannot transfer utility amongst themselves, I focus on the equilibrium strategies between $\mathrm{P}$ and a single, separated agency, Ai. Given a budget $B_{i}$ and contract $\left(\beta_{i}^{0}, \beta_{i}^{1}\right)$, Ai maximizes $u^{A i}\left(\phi_{i} ; B_{i},\left(\beta_{i}^{0}, \beta_{i}^{1}\right)\right)$ subject to $B_{i} \geq c_{i}\left(\phi_{i}\right)$. This problem is strictly concave, so the first-order condition is sufficient for characterizing the maximum. Solving for the constrained maximum:

$$
\phi_{i}^{*}\left(B_{i},\left(\beta_{i}^{0}, \beta_{i}^{1}\right)\right)= \begin{cases}\sqrt{\frac{B_{i}}{m_{i}}} & \text { if } B_{i}<\frac{\left(w_{i}-z_{i}+\beta_{i}^{1}-\beta_{i}^{0}\right)^{2}}{4 m_{i}} \\ \frac{w_{i}-z_{i}+\beta_{i}^{1}-\beta_{i}^{0}}{2 m_{i}} & \text { otherwise. }\end{cases}
$$

Now consider P's problem. Two observations simplify the problem considerably. First, $\beta_{i}{ }^{0}=0$. It is clear from [1] that only the difference in payments, $\beta_{i}{ }^{1}-\beta_{i}{ }^{0}$, matters in A $i$ 's decision; thus, for any contract such that $\beta_{i}{ }^{1}>0$ and $\beta_{i}^{0}>0, \mathrm{P}$ could do strictly better by reducing both payments by $\min \left\{\beta_{i}^{0}, \beta_{i}^{1}\right\}$. But any contract such that $\beta_{i}{ }^{1}=0$ and $\beta_{i}{ }^{0}>0$ cannot be optimal, since A $i$ would choose a weakly higher policy for lower payments if $\beta_{i}^{0}=0$. Thus, as intuition would suggest, $\mathrm{P}$ will never reward the agency for a failure.

Second, case (i) (the budget-constrained case) obtains if and only if $\phi_{i}^{A}>\phi_{i}^{P}$. To see this, suppose that $\phi_{i}^{A}>\phi_{i}^{P}$. Then as in the no-contracting case, $\mathrm{P}$ could obtain her ideal policy simply by choosing a zero contract and a budget equal to the cost of her ideal policy $\left(B_{i}=c_{i}\left(\phi_{i}^{P}\right)\right)$, resulting in case (i). If $\phi_{i}^{A} \leq \phi_{i}^{P}$, then by the concavity of $u^{A i}(\cdot)$, (i) may only obtain if $d u^{A i}\left(\phi_{i}^{*}\right) / d \phi_{i}$ $>0$. But if this were the case, then $\mathrm{P}$ could reduce $\beta_{i}^{1}$ so that $d u^{A i}\left(\phi_{i}^{*}\right) / d \phi_{i}=0$. With this revised contract, $\mathrm{P}$ would receive the same policy choice $\phi_{i}^{*}$ for a strictly lower payment. Thus, when $\phi_{i}^{A}$ $\leq \phi_{i}^{P}$, A $i$ 's ideal policy is always fully funded, though P may use a contract to induce a new (higher) ideal policy.

To find this contract, $\mathrm{P}$ maximizes: 


$$
u^{P}\left(\beta_{i}^{1}\right)=\frac{w_{i}-z_{i}+\beta_{i}^{1}}{2 m_{i}}-m_{i}\left(\frac{w_{i}-z_{i}+\beta_{i}^{1}}{2 m_{i}}\right)^{2}-\beta_{i}^{1}\left(\frac{w_{i}-z_{i}+\beta_{i}^{1}}{2 m_{i}}\right) .
$$

Solving, we find that $\beta_{i}{ }^{*}=\left(1-2\left(w_{i}-z_{i}\right)\right) / 3$ at an interior solution. Substituting back into the previous expressions yields the following characterization.

Comment 1. The unique subgame perfect Nash equilibrium strategies for each agency $A$ in the separation subgame are:

$$
\begin{aligned}
B_{i}^{*}=\left\{\begin{array}{ll}
0 & w_{i}-z_{i} \leq-1 \\
\frac{\left(w_{i}-z_{i}+1\right)^{2}}{36 m_{i}} & w_{i}-z_{i} \in\left(-1, \frac{1}{2}\right) \\
\frac{\left(w_{i}-z_{i}\right)^{2}}{4 m_{i}} & w_{i}-z_{i} \in\left[\frac{1}{2}, 1\right) \\
\frac{1}{4 m_{i}} & w_{i}-z_{i} \geq 1,
\end{array} \quad \phi_{i}^{*}= \begin{cases}0 & w_{i}-z_{i} \leq-1 \\
\frac{w_{i}-z_{i}+1}{6 m_{i}} & w_{i}-z_{i} \in\left(-1, \frac{1}{2}\right) \\
\frac{w_{i}-z_{i}}{2 m_{i}} & w_{i}-z_{i} \in\left[\frac{1}{2}, 1\right) \\
\frac{1}{2 m_{i}} & w_{i}-z_{i} \geq 1,\end{cases} \right. \\
\beta_{i}^{1^{*}}= \begin{cases}0 & w_{i}-z_{i} \leq-1 \\
\frac{1-2\left(w_{i}-z_{i}\right)}{3} & w_{i}-z_{i} \in\left(-1, \frac{1}{2}\right) \\
0 & w_{i}-z_{i} \geq \frac{1}{2},\end{cases}
\end{aligned}
$$

In equilibrium, contracts are used to induce $\mathrm{A} i$ to choose a higher policy only for moderate values of $w_{i}-z_{i}$. In the other cases, outcomes are identical to the no-contracting game. For $w_{i}-z_{i} \leq-1$, any contract that can induce A $i$ to choose a non-zero policy is too expensive for P. For $w_{i}-z_{i} \geq 1 / 2$, the policy A $i$ would have chosen in the absence of a contract is good enough for P not to use a contract. In this case, ex ante budget control is all that is necessary to secure an adequate policy.

\section{The Consolidation Subgame}

Turning to the consolidation subgame, given a budget $B$ and contract $\boldsymbol{\beta}^{C}$, A maximizes $u^{A}\left(\phi_{1}{ }^{C}, \phi_{2}{ }^{C} ; B^{C}, \boldsymbol{\beta}^{C}\right)$ subject to $B^{C} \geq c\left(\phi^{C}\right)$. This problem is also strictly concave, so the first-order condition is sufficient for characterizing the maximum. Solving for the constrained maximum:

$$
\begin{aligned}
& \phi_{1}^{C^{*}}\left(B^{C}, \boldsymbol{\beta}^{C}\right)=\frac{w_{1}-z_{1}+\beta^{10}-\beta^{00}+\left(\beta^{11}-\beta^{10}-\beta^{01}+\beta^{00}\right) \phi_{2}}{2 m_{1}(1-\lambda)}, \\
& \phi_{2}^{C^{*}}\left(B^{C}, \boldsymbol{\beta}^{C}\right)=\frac{w_{2}-z_{2}+\beta^{01}-\beta^{00}+\left(\beta^{11}-\beta^{10}-\beta^{01}+\beta^{00}\right) \phi_{1}}{2 m_{2}(1-\lambda)},
\end{aligned}
$$


where $\lambda$ is the Lagrange multiplier on the budget constraint, which equals zero when $B^{C} \geq c\left(\phi^{C *}\right)$.

This expression makes clear the relation between the policy selection problem in the two subgames: compared to [1], A's choice in each dimension depends not only on the benefit of performing that task, but potentially also on her performance of the other task. From [2], it is easily seen that the "first-order" effect of increasing A's payment from a success in one task (e.g., $\beta^{11}$ or $\beta^{10}$ for task 1 ) is to increase his effort along that dimension. However, increasing $\beta^{10}$ also decreases A's incentive to produce along task 2, and increasing $\beta^{01}$ similarly hinders his performance on task 1. Intuitively, then, each contractual payment has the effect of shifting the policy curve toward directions that are rewarded, and away from directions that are not.

Expression [2] also makes clear why at least one payment must be zero in equilibrium. An equal shift in all of the payments does not affect A's policy choice, and hence a contract with strictly positive payments cannot be optimal. Beyond this intuition, closed-form solutions for the equilibrium contracts and policies are unfortunately difficult to derive, especially when $\phi_{i}^{A} \geq \phi_{i}^{P}$ for some task $i{ }^{16}$ However, this difficulty will not hinder the derivation $\mathrm{P}$ 's choice of jurisdictional allocation. This is because a simple but important class of contracts, which I call independent contracts, facilitates comparisons between P's payoffs in the two subgames.

Independent contracts are simply those which specify payments for each task that do not depend on the outcome of the other task. Because there are only two outcomes for each separated agency, their contracts are necessarily independent. For a consolidated agency, a contract is independent if $\beta^{11}=\beta^{10}+\beta^{01}-\beta^{00}$. Inspection of [1] and [2] reveals that such a contract induces identical unconstrained ideal policies for $\mathrm{A}$ and each $\mathrm{A} i$ if $\beta^{10}-\beta^{00}=\beta_{1}{ }^{1}-\beta_{1}{ }^{0}$ and $\beta^{01}-\beta^{00}=\beta_{2}{ }^{1}-\beta_{2}{ }^{0}$. But a consolidated agency may also receive a non-independent contract. $\mathrm{P}$ could thus offer $\mathrm{A}$ an additional inducement for producing two successes, by choosing $\beta^{11}>\beta^{10}$ $+\beta^{01}-\beta^{00}$. The next comment establishes that non-independence is a basic requirement for inducing a consolidated agency to perform better than its separated counterparts.

Comment 2. If contracts are independent, then $P$ weakly prefers to separate tasks. •

\footnotetext{
${ }^{16}$ When $\phi^{A} \leq \phi^{P}$, P would never try to induce a budget-constrained policy (i.e., she does not use ex ante control), and hence $\lambda=0$. The closed form for equilibrium policies can then be derived by solving [2].
} 
The intuition behind this result is straightforward. With an independent contract, A's marginal utility for each task is unaffected by her effort on the other task. The consolidated agency's incentives can thus be duplicated by presenting separate agencies with essentially the same contract. So, critical to consolidation is P's ability to choose non-independent contracts for that agency. Such contracts link A's payments across tasks, in effect creating externalities from the performance of each.

\section{Optimal Jurisdiction Allocation}

The preceding development suggests that, in contrast to the conclusion of Proposition 1, jurisdictional arrangements can matter. If the principal can credibly commit to a nonindependent contract, it is no longer obvious that separation should always be chosen. I now complete the backwards induction analysis of the game by characterizing P's task allocation decision. This is done simply by deriving conditions under which the payoff from one subgame will be superior to that from the other.

\section{Separated Agencies}

I first examine conditions under which $\mathrm{P}$ chooses separate agencies. The first result addresses the case where the agency or agencies have higher policy ambitions than $\mathrm{P}$ for at least one task. There are two cases to consider. When $\phi^{4} \geq \phi^{P}, \mathrm{P}$ does at least as well by separating agencies because this allows her to allocate resources optimally. As with the no-contracting case, $\mathrm{P}$ can obtain her optimal policy at a minimum cost with no contractual payment. Budgetary controls alone are sufficient for making agencies fully pliant.

When $\phi_{i}^{A} \geq \phi_{i}^{P}$ for only task $i$, matters are more complicated. In this situation, a consolidated agency disagrees with P not so much over the "quantity" of policy, but over the distribution of resources across tasks. P can induce A to choose policies closer to her ideal by providing contractual inducements, and consolidation may help a bit by providing a wider range of such inducements. However, P may more easily prevent an excessive allocation of resources toward task $i$ by simply separating the agencies. Proposition 2 combines these two cases.

Proposition 2. If $\phi_{i}^{A} \geq \phi_{i}^{P}$ (alternately, if $w_{i}-z_{i} \geq 1$ ) for some task $i$, then $P$ separates tasks. • 
The result is proved by showing that $\phi_{i}^{A} \geq \phi_{i}^{P}$ for some $i$, then $\mathrm{P}$ can find a contract for separate agencies that does at least as well as that for a consolidated agency. The intuition is straightforward: for any such task $i, \mathrm{P}$ can receive her ideal policy simply by offering a budget $B_{i}$ $=c_{i}\left(\phi_{i}^{P}\right)$, without any contractual payment. This implies that if $\boldsymbol{\phi}^{4} \geq \boldsymbol{\phi}^{P}, \mathrm{P}$ can achieve her ideal outcome across both tasks. But if $\phi_{j}^{A}<\phi_{j}^{P}$ for $j \neq i$, then $\mathrm{A} j$ can be induced to choose the same policy as A would by offering them both the same expected payment for a success on task $j$. Thus, the contracts for separated agencies will be more efficient than that for a consolidated agency, as the inducements for good performance on task $j$ do not impose any externalities on the performance of task $i$.

There exists a "small" set of preference configurations under which $\mathrm{P}$ will be indifferent between the two structures. For example, if $\boldsymbol{\phi}^{A} \geq \boldsymbol{\phi}^{P}$ and $\boldsymbol{\phi}^{P}$ lies along A's policy curve, then $\mathrm{P}$ can of course achieve her ideal outcome with a consolidated agency. In addition, if $\phi_{i}^{A}$ is only slightly larger than $\phi_{i}^{P}$ and $\phi_{j}^{A}(j \neq i)$ is sufficiently low, then $\mathrm{P}$ may do as well with a consolidated agency. As the proof demonstrates, however, P's preference for separation is strict over a wide range of parameters.

\section{Consolidated Agencies}

When will P consolidate? Under the conditions of Proposition 2, a consolidated agency would allocate its resources in a way not desired by $\mathrm{P}$. By separating the agencies, $\mathrm{P}$ could receive her ideal in at least one dimension without a contract, and the displacement of effort is reduced.

When these conditions do not obtain; that is, when $\phi^{A}<\phi^{P}$, P cannot receive her ideal policy on any dimension without a contract. In this case, budgetary controls are insufficient for

attaining a policy closer to $\phi^{P}$. Here a non-independent contract can be useful, since it can give A an added incentive to increase his effort on both tasks simultaneously. The following result shows that this possibility causes $\mathrm{P}$ to prefer consolidation.

Proposition 3. If $\boldsymbol{\phi}^{4}<\boldsymbol{\phi}^{P}$ (alternately, if $w_{i}-z_{i}<1$ for all tasks $i$ ) then $P$ consolidates tasks. •

Intuitively, when $\phi^{A}<\phi^{P}$, A's preferences differ with P's over the extent, rather than the distribution, of policy. As a result, an independent contract can be designed for a consolidated 
agency that duplicates the incentives of separated agencies. With a non-independent contract, $\mathrm{P}$ can do even better, inducing A to choose a superior policy vector more efficiently than separated agencies would. Again, there is a set of preference configurations under which $\mathrm{P}$ will be indifferent between the two organizational forms. These occur when $w_{i}-z_{i}$ are sufficiently low for all $i .^{17}$ In such cases, $\mathrm{P}$ would offer no contractual payments under either structure, and thus the trivial outcome of zero budgets and policy levels result.

Figure 3 graphically depicts Propositions 2 and 3. The graph plots task assignments as a function of $\boldsymbol{\phi}^{A}$. Since $\boldsymbol{\phi}^{4}$ is defined by $w_{i}-z_{i}$, the graph is also in effect a plot of P's choice as a function of $w_{i}-z_{i} \in\left[0,2 m_{i}\right]$ for both tasks $i$.

\section{Figure 3: Separation Versus Consolidation}

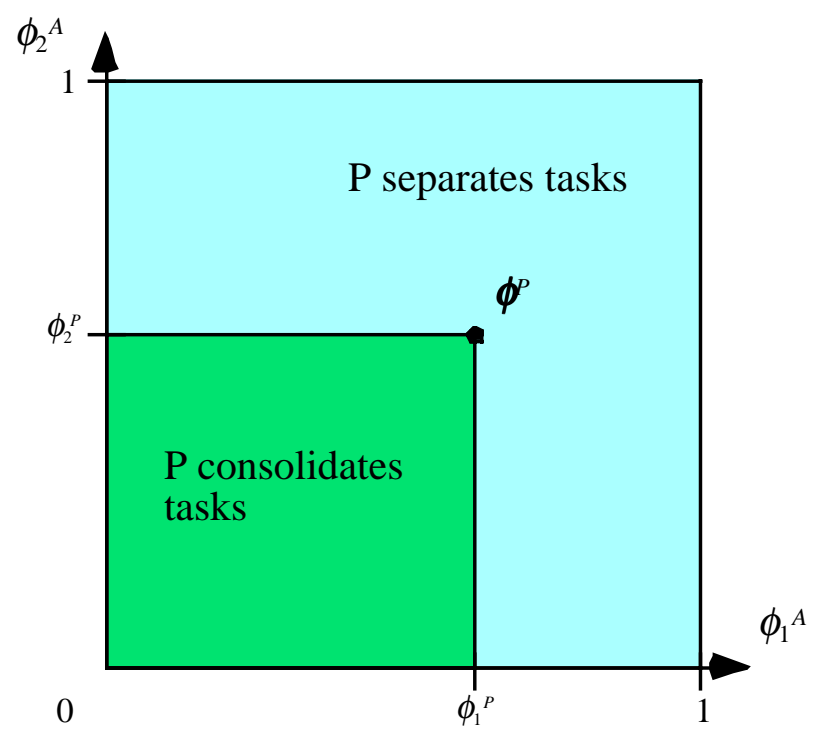

\section{A Numerical Example}

Figure 4 presents a numerical example of the jurisdiction game, where the cost function is $c(\phi)=2 \phi_{1}{ }^{2}+\phi_{2}{ }^{2}$ and $z_{1}=z_{2}=0$. The graph plots principal utility in each subgame for three values of $w_{2}\left(0.25,0.75\right.$, and 1.5) as a function of $w_{1}$, which ranges from 0 to 4 .

\footnotetext{
${ }^{17}$ As the proof of Proposition 3 shows, if $w_{i}-z_{i}>-1$ for all $i$, then the preference is strict.
} 


\section{Figure 4: Comparing Jurisdictional Assignments}

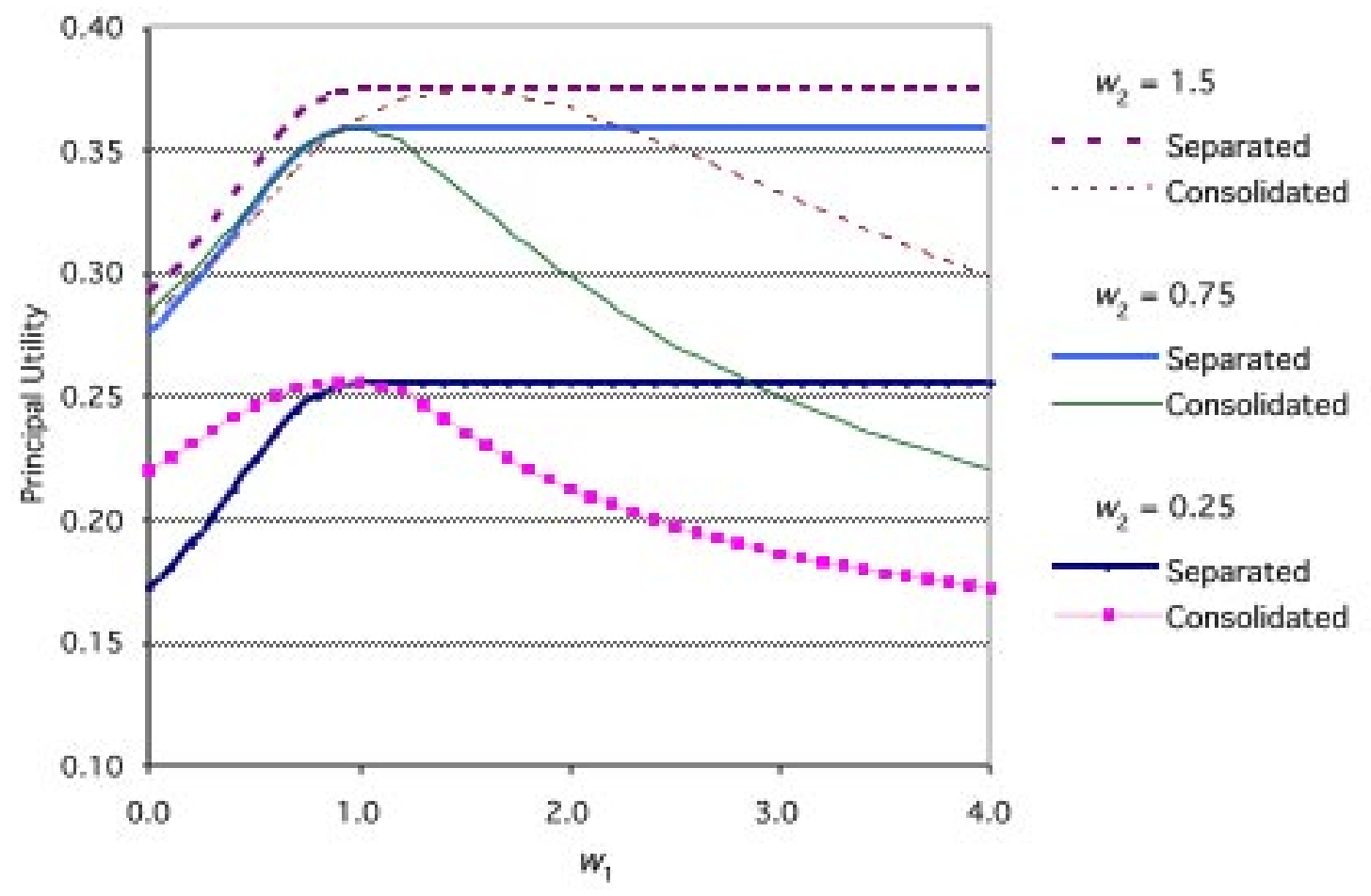

The calculations are fully consistent with the results derived above. As Proposition 3 predicts, for both $w_{2}=0.25$ and $w_{2}=0.75$, consolidation is preferred for $w_{1}<1$. As Proposition 2 predicts, for $w_{2}=1.5$ or $w_{1}>1, \mathrm{P}$ separates the tasks. In the case where $w_{2}=1.5, \mathrm{P}$ is indifferent only in the knife-edge case where $w_{1}=1.5$. Here, the consolidated agency's preferences differ with P's only in the extent, and not the distribution, of policy. P's ideal lies along the policy curve, and thus by limiting the budget appropriately, $\mathrm{P}$ does equally well under either task allocation. Finally, in all cases, as $w_{1}$ increases beyond 1, A's preferences over the allocation of resources across tasks diverge increasingly from P's. Consolidation then becomes progressively worse, while separation promises a constant payoff.

The examples also give a sense of the optimal contracts in the consolidation subgame. For example, in the $w_{2}=1.5$ case, all contractual payments are zero except for $\beta^{10}$, which is positive and decreasing for low values of $w_{1}$. When $w_{1}$ is low, raising $\beta^{10}$ is the most efficient means for offsetting A's strong preference for devoting resources toward task 2. Similarly, in the $w_{2}=0.25$ case, $\beta^{01}$ is increasing in $w_{1}$ so that $\mathrm{P}$ can maintain A's interest in performing task 2 . 


\section{Empirical Implications}

The model may be applied to a range of task allocation issues. For example, in the American military, debate has persisted over the Army and Marine Corps' role in the provision of air support for ground troops (also known as CAS, for Close Air Support). Reformers have often suggested that the current system, under which each of the four military services runs its own "air force," is redundant and wasteful (Builder 1989). However, this model provides a rationale for such a setup. Both the Army and Marines have a strong preference for CAS by virtue of their primary missions: the deployment of ground forces. These missions typically require fliers to operate in close concert with ground forces in order to deliver munitions sometimes no more than a few hundred yards from friendly troops. In fact, Marine pilots receive training both as infantry and often also as "Forward Air Controllers," or ground personnel who direct air strikes. The Air Force, by contrast, has a less direct commitment to support ground forces, and has therefore traditionally stressed the destruction of targets farther from the line of battle. This task, known as "battlefield air interdiction" (BAI), has numerous attractions, as it emphasizes strategic (as opposed to tactical) gains, requires larger and more expensive aircraft, requires less inter-service coordination, and carries less risk of friendly casualties.

How might the Air Force react if given the CAS role? A consolidated agency with a strong predilection for one task (i.e., BAI) over another (i.e., CAS) can be expected to divert resources away from the latter toward the former. As Proposition 2 suggests, the principal would be better off separating the tasks across agencies. By contrast, both the Army and Marine Corps have a relatively high demand for CAS, along with their traditional roles of deploying ground forces. These services would likely suffer fewer allocative distortions between CAS and their other tasks, and to the extent that Congress agrees with these goals, the consolidation of these tasks is sensible. Thus, despite the apparent overlap of hardware, the existing integrated airground force structures in the Army and Marines can be expected to perform better than one in which the Air Force handled all military aircraft.

The model is also amenable to a more rigorous analysis. It predicts variations in the assignment of new tasks, as well as the rearrangement of existing jurisdictions, depending on Congress' and the agencies' relative demands for bureaucratically-provided services. In 
particular, two of the most straightforward hypotheses are as follows:

(H1) Agencies will be created for new tasks when they are higher demanders than Congress; new tasks will be folded into existing agencies if they are lower demanders.

(H2) Agencies will merge when they are lower demanders than Congress; agencies will be split when they are higher demanders. ${ }^{18}$

Examples of $\mathrm{H} 1$ include the formation of the Consumer Product Safety Commission and the Federal Bureau of Investigation's investigation of organized crime. Examples of $\mathrm{H} 2$ include the 1947 split of the US Army in to the modern Air Force and Army, and the 1958-1960 consolidation of the National Advisory Committee for Aeronautics, the Naval Research Laboratory, and the Army Ballistic Missile Agency's Jet Propulsion Laboratory and Developments Operation Division into the National Aeronautics and Space Administration.

Simple tests of both hypotheses can be constructed using data on presidential preferences (as a crude measure of agency demand) and median congressional roll call scores. The latter can be augmented with the composition of relevant legislative committees and, in some specifications, party control. Additionally, measures of each agency's demand can be refined even further by considering its institutional setting; for example, highly insulated agencies (e.g., independent commissions) created by liberal coalitions might more effectively resist conservative presidents. For the dependent variables, data on bureaucratic reorganization (for $\mathrm{H} 2$ ) and the assignment of new tasks (H1) can be compiled from surveys of significant legislation (e.g., Mayhew 1991).

\section{Conclusions}

It has long been recognized that bureaucratic responsibilities are not haphazardly distributed, but rather serve specific political goals. Beyond this insight, however, little is known about a wide variety of circumstances under which legislatures face the challenge of assigning tasks to organizations. The theory developed here addresses the issue by examining an environment in which the bureaucracy may disagree with a legislature over the expenditure of

\footnotetext{
${ }^{18}$ A more refined hypothesis consistent with Proposition 2 is that a multi-task agency will be split when it is high demander for at least one task.
} 
resources across tasks. To improve bureaucratic compliance under uncertainty, the legislature may use budgets as ex ante constraints on feasible policies, and contracts as ex post inducements for better performance. This setup corresponds to the actual budgeting process more closely than those of standard contracting models.

The model derives intuitive predictions about task assignments. In equilibrium, consolidation allows principals to link inducements across tasks, thus giving an agency greater incentive to choose higher policies for all tasks. Separation prevents the allocative distortions that are possible when agencies control multiple tasks. As a result, when a principal prefers higher policy levels than the agencies on all tasks, tasks will be consolidated. Otherwise, tasks will be separated. In this situation, the principal can achieve her ideal policy on at least one dimension at minimum cost, and this performance is insulated from that of the other task.

Future research should expand on the model in several directions. An immediate extension would be to make agencies more active participants in the task allocation process. Among other things, this would allow a formalization of Wilson's (1989) logic for why agencies protect their "turf." In its current form, the model suggests a rationale for why even budgetmaximizing agencies would resist new tasks: in equilibrium a legislature will add tasks to realize efficiency gains, and these gains come at the expense of agency contractual payments. If, in addition to choosing policies, agencies could offer the legislature inducements for favorable treatment or exploit asymmetric information about their production technology, then they may resist unfavorable tasks or compete over favorable ones. The extended model could then serve as a basis for an equilibrium theory of when and how agencies expand, and of how an endogenous preference for turf might arise.

A second set of extensions should address the policy-making context. For example, the policy environment may be enriched to suit specific policy areas better. Such generalizations might include more dimensions, fixed or non-separable costs, and correlations in success probabilities across policy dimensions. But most importantly, the bureaucracy's institutional context deserves closer scrutiny. The legislature may be given a broader set of choices over a new agency's type (e.g., independent commissions versus departmental agencies) or departmental home (which may affect the agency preferences). Finally, since new jurisdictions are often accompanied by new principals, the model can be usefully adapted to flesh out the 
implications of common agency for the assignment of tasks. 


\section{Appendix}

Proposition 1. In the subgame perfect equilibrium of the n-task, no-contracting jurisdictional allocation game, $P$ separates tasks.

Proof. Consider three cases. For convenience, I abuse notation for $u^{P}(\cdot)$ to reflect the zero contracts in the obvious manner. First, if $\phi^{A} \leq \phi^{P}$, then $\phi^{A}$ is the equilibrium policy under both regimes, so $u^{P}\left(\mathbf{B}^{*} ; \boldsymbol{\phi}^{*}\left(\mathbf{B}^{*}\right)\right)=u^{P}\left(B^{C^{*}} ; \boldsymbol{\phi}^{C^{*}}\left(B^{C *}\right)\right)$.

Second, if $\phi^{P}<\phi^{A}$, then $\phi^{P}$ may only be chosen if $\boldsymbol{\phi}^{P}=\boldsymbol{\phi}^{C^{*}}\left(B^{C}\right)$ for some $B^{C}$. If there exists such a $B^{C}$, then $u^{P}\left(\mathbf{B}^{*} ; \boldsymbol{\phi}^{*}\left(\mathbf{B}^{*}\right)\right)=u^{P}\left(B^{C *} ; \boldsymbol{\phi}^{C^{*}}\left(B^{C^{*}}\right)\right)$; otherwise, $u^{P}\left(\mathbf{B}^{*} ; \boldsymbol{\phi}^{*}\left(\mathbf{B}^{*}\right)\right)>u^{P}\left(B^{C^{*}} ; \boldsymbol{\phi}^{C^{*}}\left(B^{C^{*}}\right)\right)$.

Third, without loss of generality, suppose that for $i \in\{1, \ldots, j\}, \phi_{i}^{A}<\phi_{i}^{P}$, and for $i \in\{j+$ $1, \ldots, n\}, \phi_{i}^{A} \geq \phi_{i}^{P}$, so that $\phi^{*}=\left(\phi_{1}^{A}, \ldots, \phi_{j}^{A}, \phi_{j+1}^{P}, \ldots, \phi_{n}{ }^{P}\right)$. By the convexity of $c(\bullet)$ and additive separability of utility functions,

$$
u^{P}\left(\mathbf{B}^{*} ; \boldsymbol{\phi}^{*}\left(\mathbf{B}^{*}\right)\right) \geq u^{P}(c(\boldsymbol{\phi}) ; \boldsymbol{\phi}) \text { for all } \boldsymbol{\phi} \leq \boldsymbol{\phi}^{*}
$$

Thus if $\boldsymbol{\phi}^{C^{*}} \leq \boldsymbol{\phi}^{*}, u^{P}\left(\mathbf{B}^{*} ; \boldsymbol{\phi}^{*}\left(\mathbf{B}^{*}\right)\right) \geq u^{P}\left(B^{C^{*}} ; \boldsymbol{\phi}^{C^{*}}\left(B^{C^{*}}\right)\right)$. If not, then $\phi_{k}^{C^{*}}>\phi_{k}^{*}$ for some $k \in\{j+1, \ldots$, $n\}$. For any such $\phi^{C^{*}}$, define a new policy vector $\phi^{C \prime}$ such that $\phi_{i}^{C \prime}=\phi_{i}^{P}$ if $\phi_{i}^{C^{*}}>\phi_{i}^{*}$ and $\phi_{i}^{C \prime}=\phi_{i}^{*}$ otherwise (so that $\phi^{C \prime} \leq \boldsymbol{\phi}^{*}$ ). Then for each such $k$, P receives $\phi_{k}^{C \prime}-c_{k}\left(\phi_{k}^{C}\right.$ ) under policy vector $\phi^{C \prime}$, and $\phi_{k}^{C^{*}}-c_{k}\left(\phi_{k}^{C^{* *}}\right)$ under policy vector $\phi^{C^{*}}$. But since $\phi_{k}^{C^{\prime \prime}}=\phi_{k}^{P}, \phi_{k}^{C^{\prime}}-c_{k}\left(\phi_{k}^{C}\right)>\phi_{k}^{C^{*}}-c_{k}\left(\phi_{k}^{C^{*}}\right)$. By the additive separability of utility functions, we obtain: $u^{P}\left(c\left(\phi^{C \prime}\right) ; \phi^{C}\right) \geq u^{P}\left(B^{C^{*}} ; \boldsymbol{\phi}^{C^{*}}\left(B^{C^{*}}\right)\right)$. However, $\boldsymbol{\phi}^{C \prime} \leq \boldsymbol{\phi}^{*}$, so by [3], $u^{P}\left(\mathbf{B}^{*} ; \boldsymbol{\phi}^{*}\left(\mathbf{B}^{*}\right)\right) \geq u^{P}\left(c\left(\boldsymbol{\phi}^{C \prime}\right) ; \boldsymbol{\phi}^{C \prime}\right)$. Combining expressions, $u^{P}\left(\mathbf{B}^{*}\right.$; $\left.\boldsymbol{\phi}^{*}\left(\mathbf{B}^{*}\right)\right) \geq u^{P}\left(B^{C *} ; \boldsymbol{\phi}^{C^{*}}\left(B^{C *}\right)\right)$. Therefore, $\mathrm{P}$ chooses to separate tasks. •

Comment 1 and Proof. This result is by derivation in the text. •

Comment 2. If contracts are independent, then $P$ weakly prefers to separate tasks.

Proof. It is sufficient to show that if $\boldsymbol{\beta}^{C}$ satisfies $\beta^{11}=\beta^{10}+\beta^{01}-\beta^{00}$, all outcomes under consolidation can be replicated with separate agencies. Substituting into $u^{A}\left(\boldsymbol{\phi}^{C} ; B^{C}, \boldsymbol{\beta}^{C}\right)$ and simplifying, A's objective under an independent contract is: 


$$
\begin{aligned}
u^{A}\left(\boldsymbol{\phi}^{C} ; B^{C}, \boldsymbol{\beta}^{C}\right)=\Sigma_{i}\left[w_{i} \phi_{i}^{C}\right. & \left.+z_{i}\left(1-\phi_{i}^{C}\right)-m_{i}\left(\phi_{i}^{C}\right)^{2}\right]+B^{C} \\
& +\left(\beta^{10}-\beta^{00}\right) \phi_{1}{ }^{C}+\left(\beta^{01}-\beta^{00}\right) \phi_{2}{ }^{C}+\beta^{00} .
\end{aligned}
$$

Let $\boldsymbol{\phi}^{C^{*}}$ be A's solution to this problem. Now suppose that $\mathrm{P}$ offers each separated agency A $i$ a budget $c_{i}\left(\phi_{i}^{C^{*}}\right)$ and the following contracts: $\beta_{1}{ }^{1}=\beta^{10}-\beta^{00}, \beta_{2}{ }^{1}=\beta^{01}-\beta^{00}, \beta_{1}{ }^{0}=0$, and $\beta_{2}{ }^{0}=0$. Then $\partial u^{A} / \partial \phi_{i}=d u^{A i} / d \phi_{i}$ for each task $i$. By the concavity of all agency objective functions, for any task such that $\phi_{i}^{*}>0, \partial u^{A}\left(\phi_{i}^{C^{*}}\right) / \partial \phi_{i} \geq 0$. Hence, $d u^{A i}\left(\phi_{i}^{C^{*}}\right) / d \phi_{i} \geq 0$ and A $i$ would choose $\phi_{i}^{C^{*}}$ if offered budget $c_{i}\left(\phi_{i}^{C^{*}}\right)$. For any task such that $\phi_{i}^{C^{*}}=0$, A $i$ would clearly choose $\phi_{i}^{C^{*}}$ if offered budget $c_{i}\left(\phi_{i}^{C^{*}}\right)$. Since $\boldsymbol{\phi}^{C^{*}}$ must be feasible under $B^{C}, B^{C} \geq c\left(\phi^{C *}\right)$. Moreover, since $\beta^{11} \geq \beta_{1}{ }^{1}+\beta_{2}{ }^{1}$, $\beta^{10} \geq \beta_{1}{ }^{1}, \beta^{01} \geq \beta_{2}{ }^{1}$, and $\beta^{00} \geq \beta_{1}{ }^{0}+\beta_{2}{ }^{0}$, the total payments to A1 and A2 for any outcome are weakly less than the payment to A. Thus $\phi^{C^{*}}$ may be implemented by separated agencies at weakly less cost and weakly lower contractual payment than with a consolidated agency. •

Proposition 2. If $\phi_{i}^{A} \geq \phi_{i}^{P}$ (alternately, if $w_{i}-z_{i} \geq 1$ ) for some task $i$, then P separates tasks.

Proof. There are two cases. First suppose that $\phi^{4} \geq \phi^{P}$. Then by Comment 1 , if $\mathrm{P}$ chooses separate agencies, she attains her ideal outcome; $B_{i}^{*}=c_{i}\left(\phi_{i}^{P}\right), \beta_{i}^{1^{*}}=\beta_{i}^{0^{*}}=0$, and $\phi_{i}^{*}=\phi_{i}^{P}$, for each Ai. $\mathrm{P}$ therefore weakly prefers to separate tasks. This preference is strict unless A would choose $\boldsymbol{\phi}^{C^{*}}\left(B^{C}, \boldsymbol{\beta}^{C}\right)=\boldsymbol{\phi}^{P}$ when $B^{C}=c\left(\boldsymbol{\phi}^{P}\right)$ and $\boldsymbol{\beta}^{C}=\mathbf{0}$. To determine conditions under which this is possible, consider A's maximization problem. There are five constraints; (i) $B^{C} \geq c(\boldsymbol{\phi})$, (ii) $\phi_{1} \leq$ 1 , (iii) $\phi_{2} \leq 1$, (iv) $\phi_{1} \geq 0$, and (v) $\phi_{2} \geq 0$. Because it is assumed that $\boldsymbol{\phi}^{4} \geq \boldsymbol{\phi}^{P}$ and $\boldsymbol{\phi}^{P}<\mathbf{1}$, (ii)-(v) are slack, and I disregard them. Given budget $B^{C}$ and $\boldsymbol{\beta}^{C}=\mathbf{0}$, A's Lagrangian is:

$$
\boldsymbol{L}=\boldsymbol{\Sigma}_{i}\left[w_{i} \phi_{i}+z_{i}\left(1-\phi_{i}\right)-m_{i} \phi_{i}^{2}\right]+\mu\left(B^{C}-m_{1} \phi_{1}^{2}-m_{2} \phi_{2}^{2}\right)+B^{C} .
$$

Differentiation yields:

$$
\frac{\partial \boldsymbol{L}}{\partial \phi_{i}}=w_{i}-z_{i}-2 m_{i} \phi_{i}-2 m_{i} \mu \phi_{i} \leq 0
$$

so that $\phi_{1}=\phi_{2} m_{2}\left(w_{1}-z_{1}\right) /\left(m_{1}\left(w_{2}-z_{2}\right)\right)$. Since $\boldsymbol{\phi}^{P}=\boldsymbol{\phi}^{A}$ when $w_{1}-z_{1}=w_{2}-z_{2}=1, \boldsymbol{\phi}^{C *}\left(c\left(\boldsymbol{\phi}^{P}\right), \boldsymbol{\beta}^{C}=\right.$ $\mathbf{0})=\boldsymbol{\phi}^{P}$ only if $w_{1}-z_{1}=w_{2}-z_{2} \geq 1$. This is clearly a measure zero case. 
Second, suppose without loss of generality that $\phi_{1}{ }^{A} \geq \phi_{1}{ }^{P}$ and $\phi_{2}^{A}<\phi_{2}^{P}$. I first establish two necessary conditions for consolidation to be preferred to separation.

Claim 1: P prefers consolidation only if $\phi_{1}{ }^{*}=\phi_{1}{ }^{P}$. Suppose not. I construct contracts for separated agencies such that $\phi_{1}{ }^{C^{*}}=\phi_{1}{ }^{P}$ that result in strictly superior outcomes for P. Define contracts $\left(\boldsymbol{\beta}_{1}^{\prime}, \boldsymbol{\beta}_{2}\right)$ so that $\beta_{1}{ }^{0 \prime}=\beta_{1}{ }^{\prime \prime}=\beta_{2}{ }^{\prime \prime}=0$, and $\beta_{2}{ }^{\prime \prime}=\max \left\{0,\left(\beta^{01^{*}}-\beta^{00^{*}}\right)\left(1-\phi_{1}{ }^{C^{*}}\right)+\left(\beta^{11^{*}}-\right.\right.$ $\left.\left.\beta^{10^{*}}\right) \phi_{1}^{C^{*}}\right\}$. Then by [1] and [2], for budgets $B_{1}=c_{1}\left(\phi_{1}{ }^{P}\right)$ and $B_{2}=c_{2}\left(\phi_{2}{ }^{C^{*}}\right)$, A1 and A2 choose $\phi_{1}{ }^{P}$ and $\phi_{2}{ }^{{ }^{*}}$, respectively. $\mathrm{P}$ thus receives a strictly superior policy and budget combination with separate agencies. P also makes lower expected contractual payments with separated agencies if:

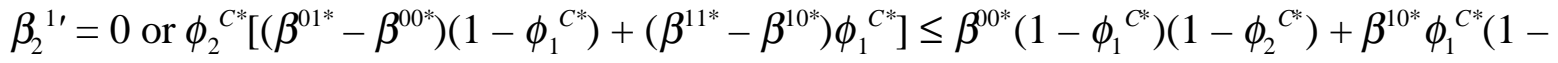
$\left.\phi_{2}^{C^{*}}\right)+\beta^{01^{*}}\left(1-\phi_{1}{ }^{C *}\right) \phi_{2}^{C^{*}}+\beta^{11^{*}} \phi_{1}^{C^{*}} \phi_{2}^{C^{*}}$, or $\beta^{00^{*}}\left(1-{\phi_{1}}^{C^{*}}\right)+\beta^{10^{*}} \phi_{1}^{C^{*}} \geq 0$, which holds trivially. Contradiction. Thus $\mathrm{P}$ prefers separation if $\phi_{1}^{C^{*}} \neq \phi_{1}{ }^{P}$.

Claim 2: P prefers consolidation only if $\phi_{2}{ }^{*}=\phi_{2}{ }^{*}$. Suppose not. Given Claim $1, \phi^{C^{*}}=$ $\left(\phi_{1}{ }^{P}, \phi_{2}{ }^{C *}\right)$, while $\phi_{1}{ }^{*}=\phi_{1}{ }^{P}$. By choosing $\boldsymbol{\beta}_{2}{ }^{\prime}$ as defined above, $\mathrm{P}$ can induce A2 to choose $\phi_{2}{ }^{{ }^{*}}$ with the same expected contractual payments as in the consolidation subgame. But since $\mathrm{P}$ ideally prefers a contract inducing A2 to choose $\phi_{2}{ }^{*}$, she prefers separation: contradiction.

Thus consolidation can only be preferred by $\mathrm{P}$ if $\boldsymbol{\phi}^{C^{*}}=\phi^{*}$ (note that $\phi_{1}{ }^{P}=\phi_{1}{ }^{*}$ ). Since $\phi^{*}$ is achieved with the minimal budget and expected contractual payment under separation, separation is weakly preferred for $\phi_{1}{ }^{A} \geq \phi_{1}^{P}$ and $\phi_{2}{ }^{A}<\phi_{2}{ }^{P}$.

Note finally that if $w_{2}-z_{2}>1 / 2$, the preference for separation is strict. In this case, $\mathrm{P}$ makes no contractual payments under separation, but since $\boldsymbol{\phi}^{*} \neq \boldsymbol{\phi}^{C^{*}}\left(B^{C} ; \boldsymbol{\beta}^{C}=\mathbf{0}\right)$ for any budget $B^{C}$, a positive contractual payment is necessary to induce A to choose $\boldsymbol{\phi}^{*}$. $\bullet$

Proposition 3. If $\phi^{4}<\phi^{P}$ (alternately, if $w_{i}-z_{i}<1$ for all tasks $i$ ) then $P$ consolidates tasks.

Proof. It is sufficient to show that $\mathrm{P}$ does at least as well under the consolidation subgame as under the separation subgame. Let $B_{i}{ }^{*}, \boldsymbol{\beta}_{i}{ }^{*}$, and $\phi_{i}{ }^{*}$ represent the equilibrium strategies in the separation subgame. Now let $\mathrm{P}$ offer budget $B^{C^{\prime}}=B_{1}{ }^{*}+B_{2}{ }^{*}$ and the following contract $\boldsymbol{\beta}^{C \text { ' }}$ to the consolidated agency, $\mathrm{A}: \beta^{00 \prime}=0, \beta^{10 \prime}=\beta_{1}{ }^{{ }^{*}}, \beta^{0{ }^{\prime}}=\beta_{2}{ }^{1^{*}}$, and $\beta^{1{ }^{\prime \prime}}=\beta_{1}{ }^{1^{*}}+\beta_{2}{ }^{1^{*}}$. Then A's objective is: $u^{A}\left(\boldsymbol{\phi} ; B^{C \prime}, \boldsymbol{\beta}^{C}\right)=\boldsymbol{\Sigma}_{i}\left[w_{i} \phi_{i}+z_{i}\left(1-\phi_{i}\right)-m_{i} \phi_{i}{ }^{2}\right]+B^{C \prime}+\beta_{1}{ }^{1 *} \phi_{1}+\beta_{2}{ }^{1 *} \phi_{2}$. Since $u^{A}(\bullet)$ is concave, first-order conditions are sufficient to characterize a maximum. A would therefore choose, if 
feasible, $\phi_{i}^{C \prime}=\max \left\{0,\left(w_{i}-z_{i}+\beta_{i}^{1^{*}}\right) / 2 m_{i}\right\}$. By Comment $1, \phi_{i}^{C \prime}=\phi_{i}^{*}$ for all tasks $i$. Thus, $\phi_{i}^{C \prime}$ is feasible under budget $B^{C \prime}$. P therefore receives the same utility by offering budget $B^{C \prime}$ and contract $\boldsymbol{\beta}^{C \prime}$ in the consolidation game as she receives in equilibrium of the separation subgame. Therefore, $\mathrm{P}$ weakly prefers to consolidate tasks.

I show finally that if additionally $w_{i}-z_{i}>-1$ for all tasks $i$, this preference is strict. Suppose otherwise; i.e., that $\beta^{C \prime}$ is optimal. Calculating $\partial u^{P} / \partial \beta^{11}$, we obtain:

$$
\begin{aligned}
\frac{\partial u^{P}}{\partial \beta^{11}}=\sum_{i} & {\left[\frac{\partial \phi_{i}^{C^{*}}}{\partial \beta^{11}}-2 m_{i} \phi_{i}^{C^{*}}(\bullet) \frac{\partial \phi_{i}^{C^{*}}}{\partial \beta^{11}}\right]-\beta^{11}\left(\phi_{2}^{C^{*}} \frac{\partial \phi_{1}^{C^{*}}}{\partial \beta^{11}}+\phi_{1}^{C^{*}} \frac{\partial \phi_{2}^{C^{*}}}{\partial \beta^{11}}\right) } \\
& -\beta^{10}\left(\frac{\partial \phi_{1}^{C^{*}}}{\partial \beta^{11}}-\phi_{2}^{C^{*}} \frac{\partial \phi_{1}^{C^{*}}}{\partial \beta^{11}}-\phi_{1}^{C^{*}} \frac{\partial \phi_{2}^{C^{*}}}{\partial \beta^{11}}\right)-\beta^{01}\left(\frac{\partial \phi_{2}^{C^{*}}}{\partial \beta^{11}}-\phi_{2}^{C^{*}} \frac{\partial \phi_{1}^{C^{*}}}{\partial \beta^{11}}-\phi_{1}^{C^{*}} \frac{\partial \phi_{2}^{C^{*}}}{\partial \beta^{11}}\right) \\
& -\beta^{00}\left(-\frac{\partial \phi_{1}^{C^{*}}}{\partial \beta^{11}}-\frac{\partial \phi_{2}^{C^{*}}}{\partial \beta^{11}}+\phi_{2}^{C^{*}} \frac{\partial \phi_{1}^{C^{*}}}{\partial \beta^{11}}+\phi_{1}^{C^{*}} \frac{\partial \phi_{2}^{C^{*}}}{\partial \beta^{11}}\right) .
\end{aligned}
$$

Since $\beta^{00 \prime}=0$ and $\beta^{11 \prime}=\beta^{10 \prime}+\beta^{01 \prime}, \partial u^{P} / \partial \beta^{11}$ evaluated at $\boldsymbol{\beta}^{C \prime}$ simplifies to:

$$
\frac{\partial u^{P}\left(\boldsymbol{\beta}^{C \prime}, \cdot\right)}{\partial \beta^{11}}=\left(1-\beta^{10 \prime}-2 m_{1} \phi_{1}^{C \prime}\right) \frac{\partial \phi_{1}^{C^{*}}}{\partial \beta^{11}}+\left(1-\beta^{\left.01 \prime^{\prime}-2 m_{2} \phi_{2}^{C \prime}\right)} \frac{\partial \phi_{2}^{C^{*}}}{\partial \beta^{11}} .\right.
$$

Substituting from Comment $1,1+\beta^{10 \prime}-2 m_{1} \phi_{1}{ }^{C \prime}>0$ if $w_{1}-z_{1}<1$, and likewise $1+\beta^{01 \prime}-2 m_{2} \phi_{2}{ }^{C^{\prime}}$ $>0$ if $w_{2}-z_{2}<1$. Thus $\partial u^{P} / \partial \beta^{11}>0$ if $\partial \phi_{i}^{C^{*}} / \partial \beta^{11}>0$ for all $i$. Now $\partial \phi_{1}^{C^{*}} / \partial \beta^{11}$ evaluated at $\boldsymbol{\beta}^{C \prime}$ simplifies to:

$$
\frac{\partial \phi_{1}^{C^{*}}}{\partial \beta^{11}}=\frac{w_{2}-z_{2}+\beta^{01}}{4 m_{1} m_{2}}
$$

Then by Comment $1, \partial \phi_{1}{ }^{C^{*}} / \partial \beta^{11}>0$ for $w_{2}-z_{2}>-1$. A symmetric statement obtains for $\partial \phi_{2}^{C^{*}} / \partial \beta^{11}$. Thus if $w_{i}-z_{i} \in(-1,1)$ for all tasks $i, \partial u^{P}\left(\boldsymbol{\beta}^{C_{1}}, \bullet\right) / \partial \beta^{11}>0$. P would achieve a higher utility by choosing $\beta^{11}>\beta_{1}{ }^{{ }^{*}}+\beta_{2}{ }^{{ }^{*}}$ : contradiction. Therefore $\beta^{\text {C' }}$ cannot be the optimal contract, and $\mathrm{P}$ can achieve a strictly higher utility under consolidation than with the optimal contract under separation. • 


\section{References}

Banks, Jeffrey S. 1989. "Agency Budgets, Cost Information, and Auditing." American Journal of Political Science 33: 670-699.

Banks, Jeffrey S. and Barry R. Weingast. 1992. "The Political Control of Bureaucracies Under Asymmetric Information.” American Journal of Political Science 36: 509-524.

Bendor, Jonathan B. 1985. Parallel Systems. Berkeley: University of California Press.

Bendor, Jonathan B. and Terry M. Moe. 1985. "An Adaptive Model of Bureaucratic Politics." American Political Science Review 79: 755-774.

Bendor, Jonathan B., Serge Taylor, and R. Van Gaalen. 1987. "Politicians, Bureaucrats, and Asymmetric Information." American Journal of Political Science 31: 796-828.

Builder, Carl H. 1989. The Masks of War: American Military Styles in Strategy and Analysis. Baltimore: Johns Hopkins University Press.

Calvert, Randall L., Mathew D. McCubbins, and Barry R. Weingast. 1989. "A Theory of Political Control and Agency Discretion.” American Journal of Political Science 33: 588-611.

Cyert, Richard M., and James G. March. 1963. A Behavioral Theory of the Firm. Englewood Cliffs, NJ: Prentice-Hall.

de Figueiredo, Rui. 1998. "The Strategic Use of Agency Jurisdictions: Applications of MultiTask Agency Theory to the Understanding of Bureaucracies." Paper presented at the Annual Meetings of the American Political Science Association.

Derthick, Martha. 1990. Agency Under Stress: The Social Security Administration in American Government. Washington DC: The Brookings Institution.

Dixit, Avinash K. 1995. The Making of Economic Policy: A Transaction Cost Politics Perspective. Cambridge, MA: MIT Press.

Epstein, David, and Sharyn O'Halloran. 1999. Delegating Powers: A Transaction Cost Politics Approach to Policy Making Under Separate Powers. New York: Cambridge University Press.

"Evaluation of the Organizational Structure and Management Practices of the California Department of Transportation - Progress Report on Caltrans' Implementation Efforts." SRI International, March 1996.

Hammond, Thomas H. 1979. Jurisdictional Preferences and the Choice of Tasks: Political Adaptation by Two State Wildlife Departments. Doctoral Dissertation, University of California at Berkeley.

Heimann, C. F. L. 1993. "Understanding the Challenger Disaster: Organizational Structure and the Design of Reliable Systems." American Political Science Review 87: 421-435. 
Holmstrom, Bengt, and Paul Milgrom. 1991. "Multi-task Principal-Agent Analyses: Incentive Contracts, Asset Ownership and Job Design." Journal of Law, Economics, and Organization 7: 24-52.

Kaufman, Herbert. 1960. The Forest Ranger: A Study in Administrative Behavior. Baltimore: Johns Hopkins University Press.

Kaufman, Herbert. 1976. Are Government Organizations Immortal? Washington, DC: The Brookings Institution.

Kaufman, Herbert. 1981. The Administrative Behavior of Federal Bureau Chiefs. Washington, DC: The Brookings Institution.

Landau, Martin. 1969. "Redundancy, Rationality, and the Problem of Duplication and Overlap." Public Administration Review 29: 346-358.

Mayhew, David. 1991. Divided We Govern: Party Control, Lawmaking, and Investigations, 1946-1990. New Haven, CT: Yale University Press.

McCubbins, Mathew, Roger Noll, and Barry R. Weingast. 1987. "Administrative Procedures as Instruments of Political Control.” Journal of Law, Economics, and Organization 3: 243-277.

Miller, Gary J., and Terry M. Moe. 1983. "Bureaucrats, Legislators, and the Size of Government." American Political Science Review 77: 297-322.

Moe, Terry M. 1989. "The Politics of Bureaucratic Structure.” In J. E. Chubb and P. E. Peterson (ed.), Can the Government Govern? Washington, DC: The Brookings Institution.

Niskanen, William A. 1971. Bureaucracy and Representative Government. Chicago: AldineAtherton.

Quirk, Paul J. 1980. "Food and Drug Administration.” In J. Q. Wilson (ed.) The Politics of Regulation. New York: Basic Books.

Silver, Jay. 1996. "Influencing Agency Policies Through Congressional Appropriations." Mimeo. Stanford GSB.

Tullock, Gordon. 1965. The Politics of Bureaucracy. Washington, DC: Public Affairs Press.

Wilson, James Q. 1989. Bureaucracy. New York: Basic Books. 